\title{
Influence of Fly Ash Denitrification on Properties of Hybrid Alkali Activated Composites
}

\author{
Lukáš Procházka *, Jana Boháčová and Barbara Vojvodíková
}

Faculty of Civil Engineering, VSB- Technical University of Ostrava, L. Podeste 1875, Ostrava- Poruba, 70800, Czech Republic; jana.bohacova@vsb.cz (J.B.); barbara.vojvodikova@vsb.cz (B.V)

* Correspondence: lukas.prochazka@vsb.cz (L.P.)

\begin{abstract}
This article deals with the possibility of partial replacement of blast furnace slag with fly ash after denitrification by the Selective Non-Catalytic Reduction (SNCR) method in alkali-activated materials. In the experiment, the basic physical-mechanical properties and durability properties were tested, the hydration reaction was monitored in a calorimeter and infrared spectroscopy was performed. Results were compared between mixtures prepared with fly ash without denitrification and also with reference mixture based only on alkali-activated blast furnace slag. The basic result is the finding, that hybrid alkali-systems with fly ash after denitrification show similar trends as hybrid alkali-systems with fly ash without denitrification. The significant effect of fly ash is manifested especially in terms of resistance to freeze-thaw. The reactions in the calorimeter show a slower development of reactions with increasing replacement of slag by fly ash. In the case of testing resistance to leaching in demineralised water, a decrease of flexural strength was found, which corresponds to the conclusions of strength testing, that long-term deposition of bodies in water causes deterioration of mechanical properties.
\end{abstract}

Keywords: blast furnace granulated slag; silica fly ash; alkali-activated materials; denitrification; material engineering.

\section{Introduction}

Various materials are used for the preparation of alkali-activated materials, such as blast furnace granulated slag, fly ash, metakaolin and others. Each of this input material has its advantages and disadvantages. Blast furnace granulated slag is characterized by a rapid reaction in the initial stages of maturation, which corresponds to high initial strength. On the other hand, alkali-activated slag is characterized by high shrinkage, which may cause shrinkage cracks [1, 2, 3].

Disadvantages of alkali-activated fly ash include low reactivity at normal temperatures, which results in these materials being warmed $[2,4,5]$.

In order to reduce the disadvantages of the individual input materials, the use of these materials in hybrid alkali-activated materials has been investigated in $[1,2,6,7]$.

In the case of binary hybrid alkali-activated materials based on blast furnace granulated slag, by adding fly ash we achieve an increase in the content of alumina and silica without an increase in the content of calcium oxide. This partial replacement will affect the mechanism and rate of formation hydration products. [2] Alkali-activated slag produces hydration products based on C-(A)-S-H gel and in the case of activated fly ash, hydration products based on N-A-S-H gel are formed [2, 8-12].

In hybrid slag-fly ash systems, above-mentioned hydration products may be formed at the same time, if the amount of fly ash does not exceed $75 \%$ and if the amount of slag is about $50 \%$ or less. To form a hybrid gel in the form of N-(C)-A-S-H gel, dissolved $\mathrm{Ca}^{2+}$ is incorporated into the structure of the N-A-S-H gel, which is formed by the activation of fly ash. Due to slower reactions in systems with a lower content of blast furnace granulated slag, more crosslinked products and a denser microstructure are formed. The use of products based on slag and fly ash leads to the formation of a common binder and the formation of a large amount of tetracoordinated Al charge-balanced by Na in a hydrated 
system $\mathrm{Na} 2 \mathrm{O}-\mathrm{CaO}-\mathrm{Al}_{2} \mathrm{O}_{3}-\mathrm{SiO}_{2}$. However, the final hydration products depend on factors such as curing conditions, the type and concentration of activator and the amount of slag and fly ash in the mixture [2].

Some studies indicate, that in addition to the main hydration product (C-(A)-S-H gel), hydrotalcite-like phases are formed in alkali-activated blast furnace slag systems. These are phases of bilayer hydroxides based on Mg-Al. Hydrotalcite has a positive effect on durability properties, such as the resistance to penetration of carbon dioxide chlorides and sulphates [13, 14].

Studies show that the hydrotalcite phases may be in the form of plate or lath precipitates, or may be present in a very fine scale in the internal structure of the C-A-S-H gel [13].

The effect of temperature on the workability of alkali-activated slag was studied in [15]. Different alkaline activators achieved different properties. For the sodium silicate solution, a significant reduction of workability and a shortening of the onset of solidification time was observed as the temperature increased from $20^{\circ} \mathrm{C}$ to $31^{\circ} \mathrm{C}$. Sodium hydroxide and sodium carbonate improved workability and prolonged setting time as the temperature rose to $26{ }^{\circ} \mathrm{C}$. A further increase of temperature to $31^{\circ} \mathrm{C}$ then had a significant effect on the deterioration of workability and the shortening of the setting time [15]

The effect of temperature on the processability of alkali-activated fly ash-based pastes was studied in [16]. The loss of fluidity was monitored using the minislump tests by dividing the spread flow method. At $25^{\circ} \mathrm{C}$, the fluidity remains constant during the first 30 minutes, regardless of the activator used, indicating that the fly ash does not react at this temperature. While at $65^{\circ} \mathrm{C}$ the activator plays a major role in fluid loss. With the sodium hydroxide activator, the fluidity is constant, on the other hand, the combination of sodium hydroxide and sodium silicate results in a significant loss of fluidity. At a temperature of $85^{\circ} \mathrm{C}$, there is a rapid loss of fluidity during the first minutes, because at this temperature the fly ash dissolves fast [16].

\section{Materials and Methods}

In the experiment, fly ash from the power plant in Ostrava-Třebovice, silica fly ash after denitrification by the SNCR method (FAD) and fly ash before the introduction of the denitrification process (FA) were used. Due to the specific requirement to reduce nitrogen oxide emissions, denitrification processes are being put into practice. After the introduction of the denitrification process, the fly ash contains more or less ammonium salts. Denitrification can also change the shape of the ash grains, which can affect the behavior of prepared mixtures. Therefore, the behavior of fly ash after denitrification must be verified.

\subsection{Silica Fly Ash}

This fly ash was ground to a specific surface area near $500 \mathrm{~m}^{2} / \mathrm{kg}$. The specific weight of both used fly ashes was $2240 \mathrm{~m}^{2} / \mathrm{kg}$. The percentages of the individual oxides obtained by measuring the fluorescence spectrometer are given in Table 1 . The ammonia content released from the aqueous extract (FAD) is $22.8 \mathrm{mg} / \mathrm{kg}$. The mineralogical composition of the fly ash used was determined by X-ray diffraction. Figure 1 shows that $\mathrm{SiO}_{2}$ occurs in this fly ash mainly in the form of quartz. Other minerals represented in this fly ash include mullite, magnetite, free lime and hematite. Sillmanite mineral was also found in fly ash. This fly ash did not show a typical arc for the amorphous phase [17], so it can be assumed that this fly ash has a low reactivity, corresponding to the finding in [18], where the soluble amorphous phase content determined by cooking in $4 \mathrm{M}$ potassium hydroxide solution was only for FAD $4.17 \%$ and FA $4.58 \%$. In Figure 2 we see the particle size distribution determined by laser diffraction. The curves show that the fly ash after denitrification is slightly finer than the fly ash before denitrification. The mean particle size Q50 for fly ash after denitrification is $9.56 \mu \mathrm{m}$, while for fly ash before denitrification is $11.46 \mu \mathrm{m}$. In the Q90 region, there is a more significant difference between fly ash, when the proportion of larger particles is higher in fly ash before denitrification. The particle size on the Q90 axis 
for fly ash after denitrification is $33.08 \mu \mathrm{m}$, while for fly ash before denitrification it is 54.30 $\mu \mathrm{m}$.

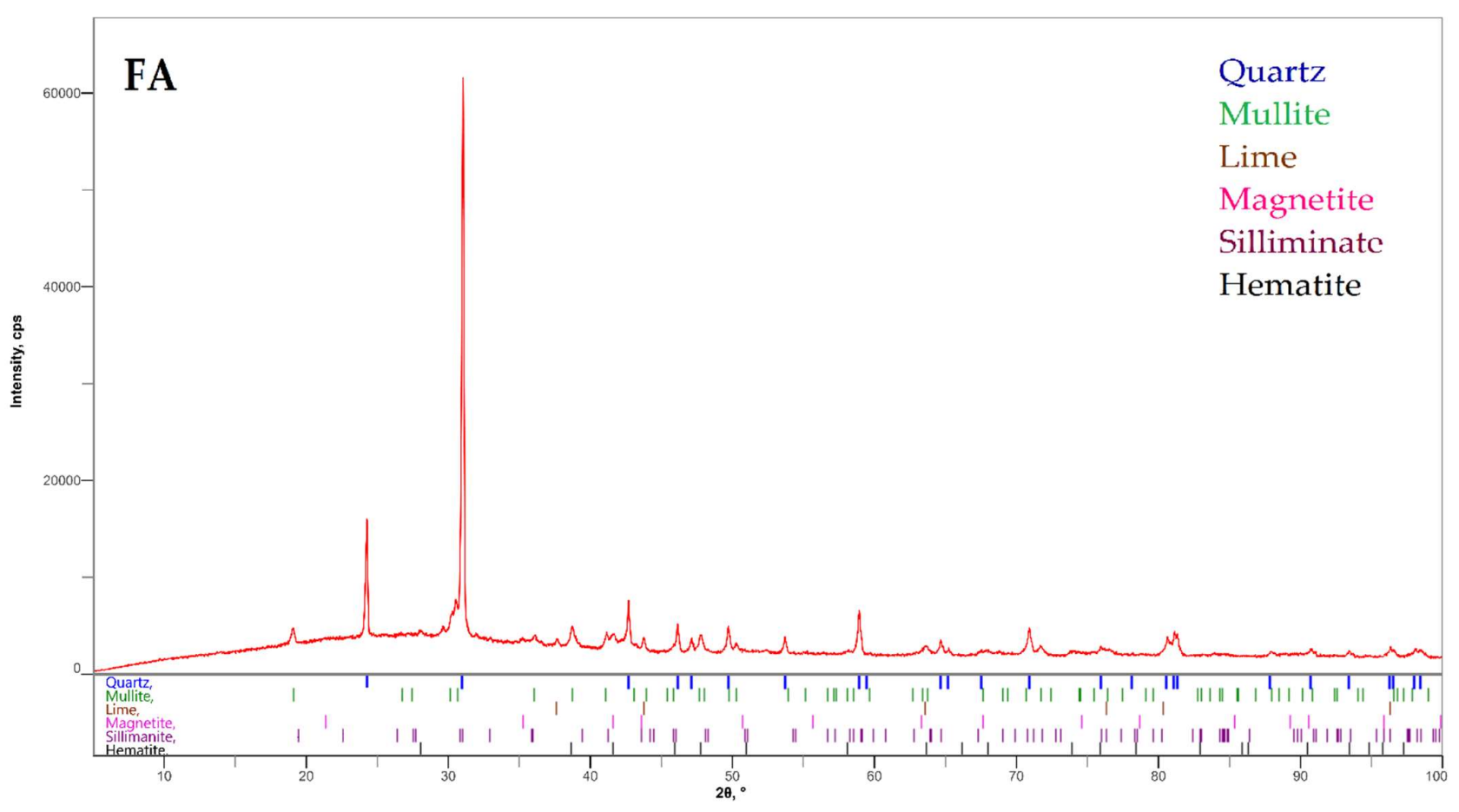


Figure 1. Mineralogical composition of FA and FAD determined by X-ray diffraction (XRD).

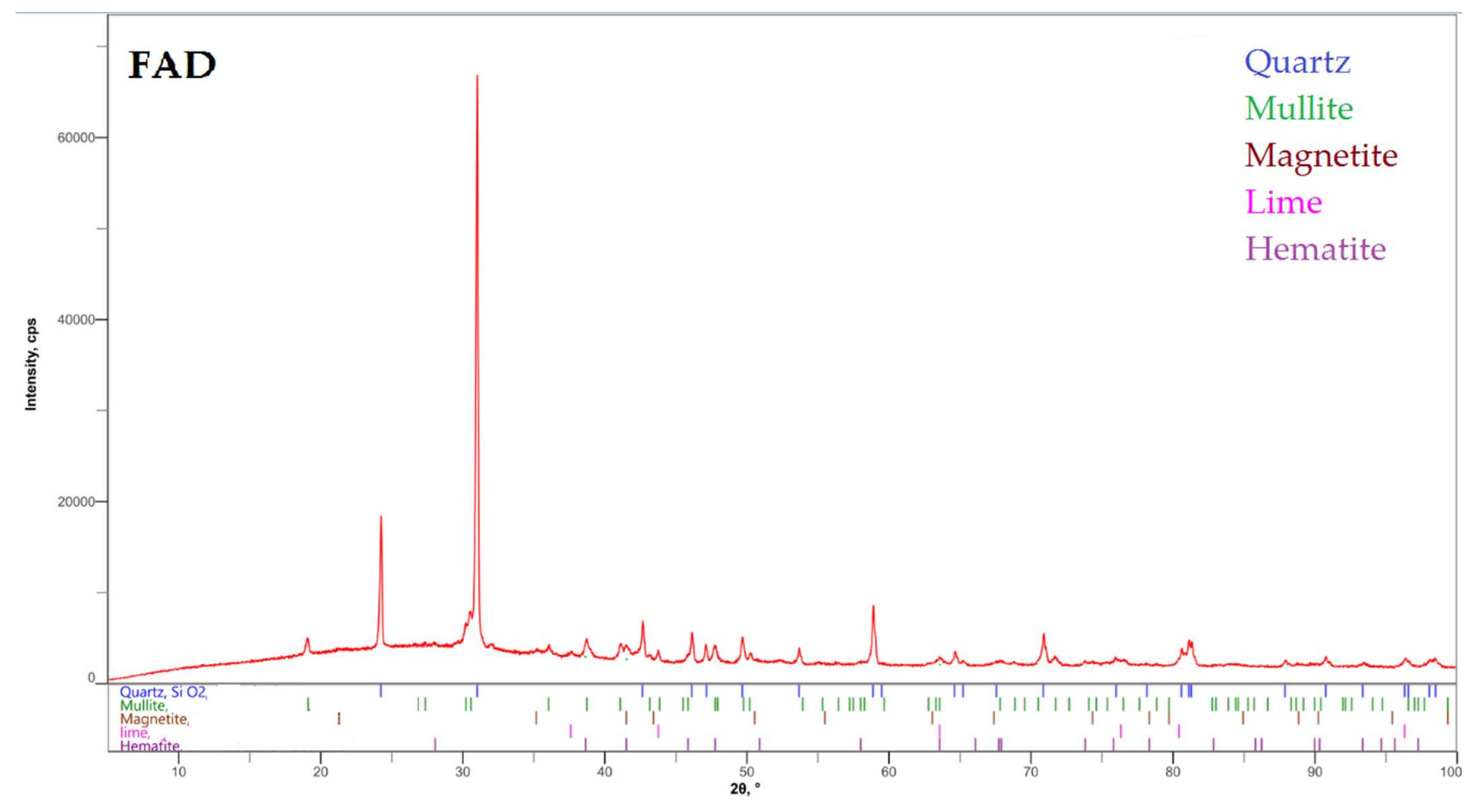




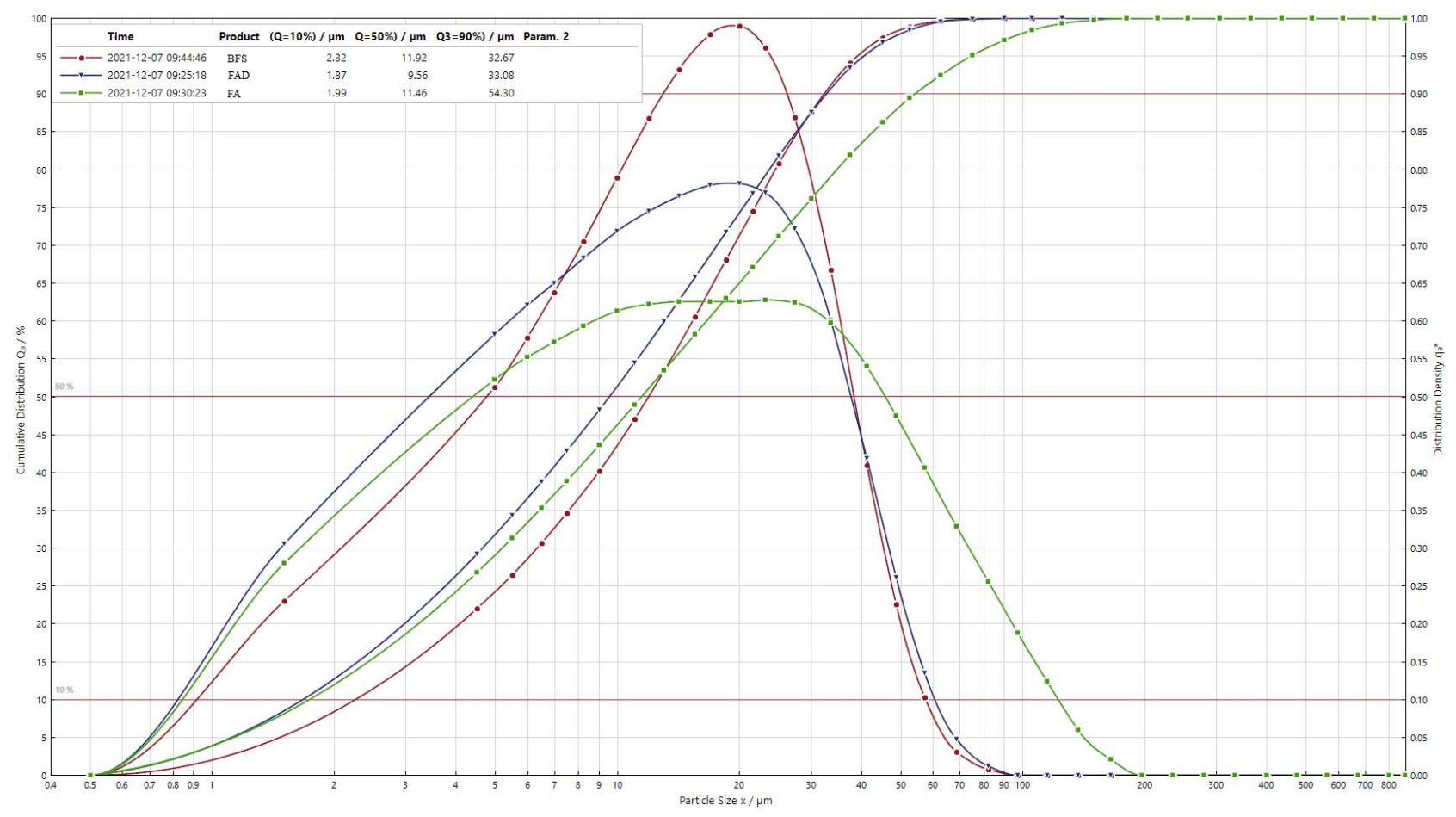

Figure 2. Determination of particle size of input raw materials by laser diffraction

Table 1. Content of selected oxides in input raw materials. (LOI-Loss on Ignition).

\begin{tabular}{cccc}
\hline \multirow{2}{*}{ Oxide } & \multicolumn{3}{c}{ Content [\%] } \\
\cline { 2 - 4 } & FAD & FA & BFS \\
\hline $\mathrm{SiO}_{2}$ & 50.89 & 48.63 & 33.81 \\
$\mathrm{Al}_{2} \mathrm{O}_{3}$ & 21.34 & 22.19 & 8.14 \\
$\mathrm{Fe}_{2} \mathrm{O}_{3}$ & 9.49 & 10.94 & 0.32 \\
$\mathrm{CaO}$ & 4.48 & 5.27 & 46.16 \\
$\mathrm{SO}_{3}$ & 0.58 & 0.83 & 1.46 \\
$\mathrm{~K} 2$ & 3.14 & 3.50 & 0.42 \\
$\mathrm{MgO}$ & 1.67 & 1.93 & 7.86 \\
$\mathrm{LOI}$ & 6.27 & 4.06 & 0.00 \\
\hline
\end{tabular}

\subsection{Blast-Blast Furnace Granulated Slag (BFS)}

For the experiment, finely ground granulated blast furnace slag was used. This slag has latent hydraulic properties and has a surface area of $\geq 400 \mathrm{~m}^{2} / \mathrm{kg}$ specified by the manufacturer and with a specific weight of $2860 \mathrm{~kg} / \mathrm{m}^{3}$. Figure 2 shows the particle size distribution of the input materials determined by laser diffraction. The mean particle size Q50 for finely ground blast furnace granulated slag is $11.92 \mu \mathrm{m}$. The percentages of individual oxides obtained by a fluorescence spectrometer measurement are shown in Table 1. The X-ray diffraction showed that the slag is highly reactive because of a high proportion of amorphous phase and that mainly minerals Akermanite, Merwinite and Calcite are present in this slag [19].

\subsection{Activator - Potassium water glass (PWG 1)}

Potassium silicate solution (Potassium water glass) with silicate modulus of 1 (Molar ratio $\mathrm{SiO}_{2} / \mathrm{K}_{2} \mathrm{O}=1$ ) was used as an activator in this experiment. The dry matter content of the water glass is $51.55 \%$. Properties of the water glass used are given in Table 2. This data is provided by the manufacturer. 
Table 2. Composition of potassium water glass (PWG 1).

\begin{tabular}{ccc}
\hline PWG 1 & Units & Value \\
\hline Content $\mathrm{SiO}_{2}$ & $\%$ & 20.24 \\
Content $\mathrm{K}_{2} \mathrm{O}$ & $\%$ & 31.31 \\
Molar weight & - & 1.01 \\
Relative density & $\mathrm{kg} / \mathrm{m}^{3}$ & 1640 \\
\hline
\end{tabular}

\subsection{Standardized Sand}

Standard sand CEN, ČSN EN 196-1 was used as aggregate in the experiment. It is natural quartz sand with a bulk density of $2640 \mathrm{~kg} / \mathrm{m}^{3}$, which is formed by rounded particles and the silica content is $\mathrm{min} .98 \%, 0 / 2 \mathrm{~mm}$ fraction and less than $0.2 \%$ moisture content [20].

\subsection{Mixtures}

This experimental part is a part of an extensive research aimed at verifying the use of fly ash after denitrification by the SNCR method in hybrid alkali-activated materials based on blast furnace granulated slag. Fly ash was also used in the research before the denitrification process was introduced. Several types of activator were used in the experiment, namely sodium water glass with silicate modulus of 1 and 2, potassium water glass with silicate modulus of 1 and 2 and anhydrous sodium metasilicate with silicate modulus of 1. Some of these results have already been published in [18, 21, 22]. Based on previous experiments on VSB-Technical University of Ostrava, a partial replacement of slag with fly ash in the range of 10, 20 and $30 \mathrm{wt}$ \% was chosen. Table 3 shows the composition of the mortars prepared in the experiment and Figure 3 shows the experimental scheme. Pastes were also prepared as a part of the experiment. No aggregate was used for the pastes. The amount of mixing water was adjusted (described in more detail in chapter 2.10). The table shows the composition of the mortar, which is based on the standard for cement testing, and is designed to fill 3 beams with dimensions of 40x40x160 mm. Similar mixtures based on the standard mix for cement testing have been published in [23].

Table 3. Mortar composition of the raw material values is given in [g].

\begin{tabular}{cccccc}
\hline Mixture & BFS & FA/FAD & PWG 1 & Water & Sand \\
\hline BFS & 450 & $\mathrm{x}$ & 96.8 & 160 & 1350 \\
10\% FA/FAD & 405 & 45 & 96.8 & 160 & 1350 \\
20\% FA/FAD & 360 & 90 & 96.8 & 160 & 1350 \\
$30 \%$ FA/FAD & 315 & 135 & 96.8 & 160 & 1350 \\
\hline
\end{tabular}

Explanation of abbreviations:

BFS - Blast-Furnace Granulated Slag; PWG 1 - Potassium water glass; FA/FAD - Fly ash/Fly ash after denitrification

\begin{tabular}{|c|c|c|c|c|c|c|}
\hline \multirow{2}{*}{$\begin{array}{l}\text { Hybrid alkali-activated } \\
\text { materials by potassium } \\
\text { water glass with silicate } \\
\text { modul } 1\end{array}$} & $\Longrightarrow$ & $\begin{array}{l}\text { Alkali- } \\
\text { activated } \\
\text { binders }\end{array}$ & $\Longrightarrow$ & $\begin{array}{c}\text { Basic physical and } \\
\text { mechanical } \\
\text { properties }\end{array}$ & $\Longrightarrow$ & $\begin{array}{c}\text { Resistance to freeze- } \\
\text { thaw and agressive } \\
\text { enviroments }\end{array}$ \\
\hline & $\Rightarrow$ & $\begin{array}{c}\text { Alkali- } \\
\text { activated paste }\end{array}$ & $\Longrightarrow$ & $\begin{array}{l}\text { The course of } \\
\text { hydration in the } \\
\text { calorimeter }\end{array}$ & $\Longrightarrow$ & $\begin{array}{c}\text { Determination of } \\
\text { FTIR }\end{array}$ \\
\hline
\end{tabular}

Figure 3. Experiment scheme.

\subsection{Preparation of Specimens}


All necessary raw materials were weighed into the mixture with a precision of $\pm 1 \mathrm{~g}$. First, binder components such as slag and fly ash were poured into the container; activator and water were added. The mixing procedure was in accordance with the requirements of Czech standards ČSN EN 196-1 and ČSN EN 196-3. The binder component, together with the addition of activator and water, was mixed for $90 \mathrm{~s}$ at a low mixing speed according to ČSN EN 196-3. At the end of the cycle, mixing occurred according to the requirements of CSN EN 196-1 with a total mixing time of 180 s, during which the sand was automatically dosed [20, 24].

After filling the molds, these were placed in a humidity cabinet at a temperature of $22 \pm 2{ }^{\circ} \mathrm{C}$ and a relative humidity of $98 \%$ for 2 days. Subsequently, the samples were demolded and stored in a water bath until testing.

\subsection{Strength}

Strength characteristics were determined on bodies with dimensions of 40x40x160 mm. To determine the basic strengths, the specimens were stored in a humidity cabinet until testing. To determine the freeze-thaw resistance, the elements were placed in a water bath after demolding.

The strengths were determined with a hydraulic press. The determination of the flexural strength was carried out by uniform loading at speeds of $(50 \pm 10) \mathrm{N} / \mathrm{s}$. The compressive strength was determined by uniform loading at a rate of $(2400 \pm 200) \mathrm{N} / \mathrm{s}$ [20].

\subsection{Resistance to freeze-thaw}

The determination of resistance to freeze-thaw occurred in a freezer with automatic cycling according to ČSN 72 2452. Cycling temperatures in the frost area were in the range of -15 to $-20^{\circ} \mathrm{C}$; a water bath with a water temperature of $20^{\circ} \mathrm{C}$ was used for thawing. One cycle consists of $4 \mathrm{~h}$ of freezing and $2 \mathrm{~h}$ of thawing [25].

\subsection{Resistance to the effects of hungry waters}

The aggressive environment was simulated with the help of demineralized water, which represented hungry water. The samples were stored in a hungry water (aggressive environments) for 1 month.

\subsection{Analytical Methods}

In order not to affect the results of the analytical methods by aggregates, pastes without aggregates were prepared. Pastes were prepared in which the ratios between BFS (FA, FAD) and activator (PWG 1) were maintained, only the amount of mixing water was reduced. As the wettability of the aggregate grains does not need to be considered for the pastes, the amount of mixing water was reduced by $71.5 \mathrm{~g}$. After the preparation of the pastes, these samples were placed in a calorimeter, in which the hydration processes were monitored and after 28 days of maturation, samples were tested for FTIR.

Infrared spectroscopy was performed on a Nicolet iS50 FT-IR instrument. The experiment used a sample compartment iS 50 ATR, a detector DTGS ATR and a beam splitter $\mathrm{kBr}$. The measurement took place in the range of $400-4000 \mathrm{~cm}^{-1}$.

X-ray diffraction was performed on a Rigaku MinyFlex instrument in the range of 5$100^{\circ} 2$ theta at a speed of $3^{\circ} / \mathrm{min}$. The D/tex Ultra 2 detector was used in the measurement and the $15 \mathrm{~mA}$ lamp voltage was $40 \mathrm{kV}$.

\section{Results and Discussion}

\subsection{Determination of Basic Physical-Mechanical Properties}

The development of the strengths of the prepared mixtures is graphically shown in Figures 4 and 5. 


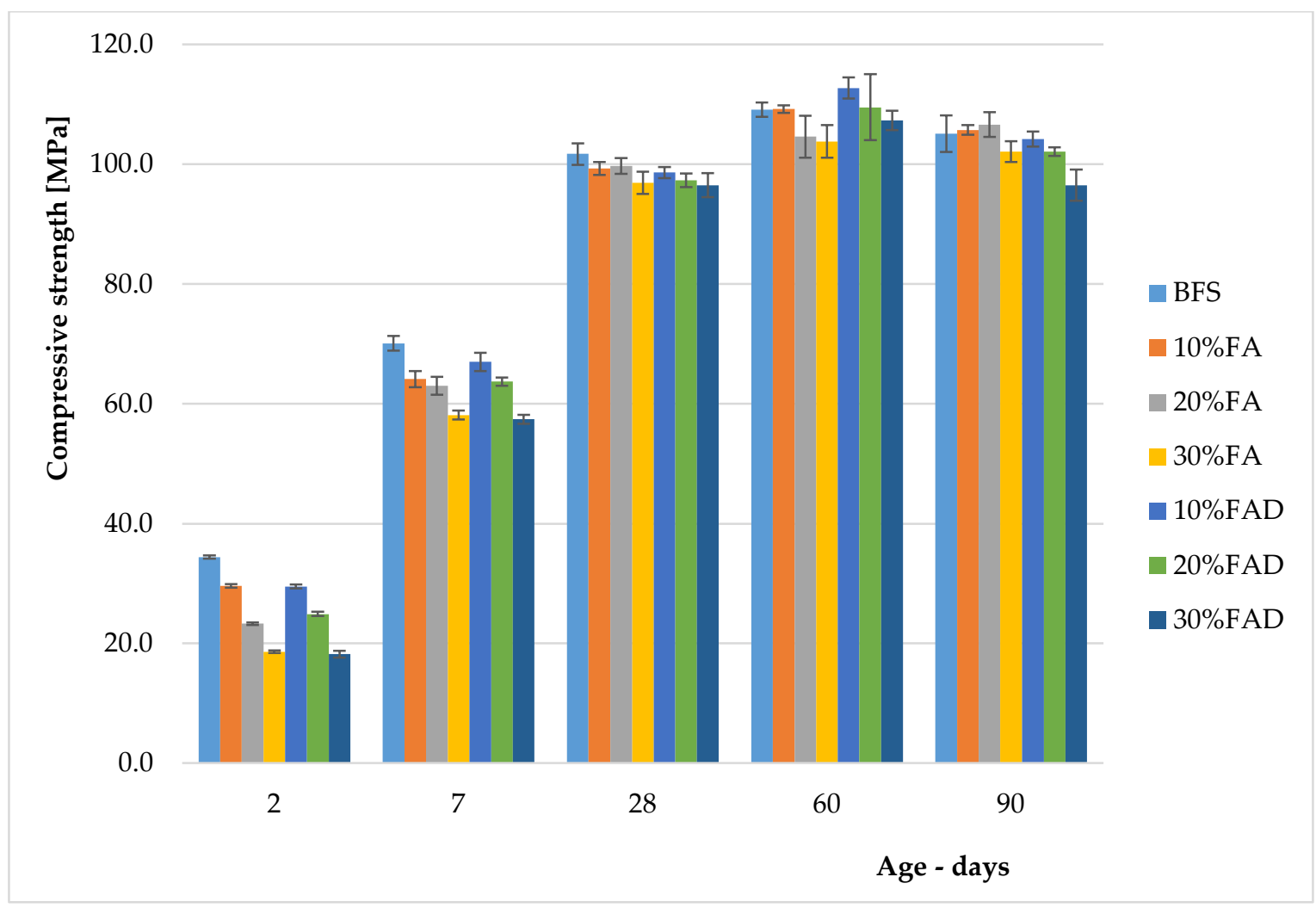

Figure 4. Compressive strength of prepared mixtures.

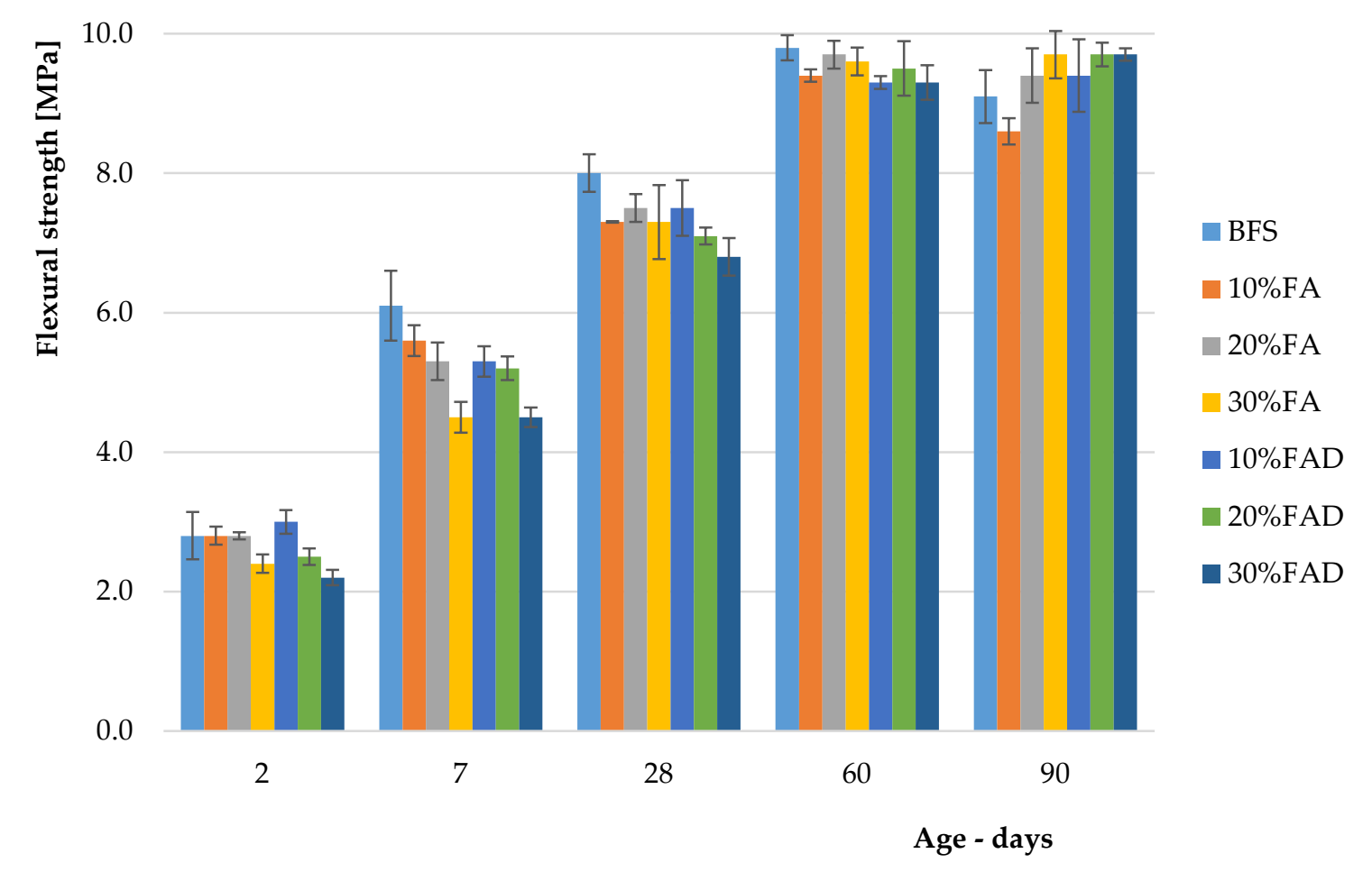

Figure 5. Flexural strength of prepared mixtures. 
From the point of view of the achieved strength, it can be concluded that the mixture with a higher replacement of slag by fly ash reduces the short-term strengths. The difference in compressive strength between the mixture of BFS and 30\% FAD after two days of maturation was $47 \%$. While after 28 days of maturation, this difference was only around $5 \%$. After 90 days of maturation, compressive strengths decreases were recorded for almost all monitored mixtures. The highest decrease was recorded for the $30 \%$ FAD mixture and was around $10 \%$.

The highest flexural strength achieved BFS mixture after 60 days. The sole exception was a higher strength value of $10 \%$ FAD mixture, that was recorded after two days of maturation. The difference in flexural strength after 28 days of maturation between the highest value of BFS mixture and the lowest value recorded for the $30 \%$ FAD mixture was around $15 \%$. But after 90 days of maturation, there were again decreases in strength for the mixtures of BFS, $10 \%$ FA and $20 \%$ FA.

There exists a similar study [18] where the same raw materials were used, the only difference was, that sodium water glass with silicate modulus 2 was used as the activator. After 90 days of maturation, the compressive strengths were almost identical and the difference was only within the standard deviation. The flexural strengths of slag activated by sodium water glass were $12 \%$ higher than in this experiment, where the mixture was activated by potassium water glass with silicate modulus of 1 . Decreases in flexural strength were also recorded. The largest decrease between 28 and 90 days of strength was achieved with the $10 \%$ FAD and was $24 \%$ [18].

The authors in [26] studied the properties of alkali-activated blast furnace granulated slag activated by sodium water glass, where the silicate modulus was treated with potassium hydroxide. When using an activator with an alkali/silica (R/S) ratio of 50/50, a flexural strength of $9.3 \mathrm{MPa}$ was achieved there, which is approximately $14 \%$ more than that of the BFS mixture. On the other hand, the compressive strength was $84.1 \mathrm{MPa}$, which is approximately $17 \%$ lower strength than the BFS mixture. Decreases in flexural strength after 90 days were also noted in this research. The highest compressive strengths in this research were recorded with the activator with a ratio (R/S) of 34/66 and 40/60 [26].

The authors in $[27,28]$ consistently state that with increasing of slag replacement, compressive strengths gradually decrease. In both of these studies, the highest strengths were achieved without partial replacement of the slag with fly ash.

In [27] the highest strengths were achieved at an alkali content of $1.5 \%$ and without replacement of slag with fly ash. After 28 days, the reached strength was around $93 \mathrm{MPa}$. When $20 \%$ slag replacement with fly ash, the strengths after 28 days were around $90 \mathrm{MPa}$, at $40 \%$ slag replacement with fly ash, the compressive strengths were around $70 \mathrm{MPa}$ [27].

In [28], the authors also monitored the development of strengths depending on the silicate modulus and on the alkali content, converted to $\mathrm{Na} 2 \mathrm{O}$. In both cases, the highest strengths were obtained at the highest alkali dose, which was $8 \%$, and at the highest silicate modulus, which was $1.5 \%$. When the strengths depending on the slag replacement were monitored, the strengths of the mixture with $100 \%$ slag were around $80 \mathrm{MPa}$, while at $40 \%$ slag replacement by fly ash the compressive strengths ranged from 40-50 MPa [28].

The authors in [29] monitored the strength characteristics of alkali-activated blast furnace slag depending on the silicate modulus and the total amount of alkalis in the mixture. Different results were obtained for compressive strengths and flexural strengths. The compressive strengths reached the highest values after 180 days of maturation at $6 \%$ alkalis in the mixture and silicate modulus 1.2. These strengths exceeded $100 \mathrm{MPa}$. The highest values of flexural strength was reached after 180 days with the lowest alkali content of $2 \%$ and the lowest silicate modulus of 0.6 , these strengths were around $11.5 \mathrm{MPa}$. On the contrary, at 7-day strengths, the highest flexural strengths were achieved at an alkali content of $5 \%$ and a silicate modulus of 1.2 , when the strengths exceeded $10 \mathrm{MPa}$. Testing later but showed decreases in strength. The authors attribute the shrinkage and decreases in strength to the redundant alkaline activator. With a higher alkali content, hydration processes can take place, which consume water from the C-S-H gel. A result, these 
hydration products self-dry over time. This drying causes a large shrinkage, which breaks bonds between the slag particles and subsequently creates cracks [29].

\subsection{Resistance to freeze-thaw}

The values of compressive strength, flexural strength and freeze-thaw resistance coefficients after 100 cycles are given in Figure 6. Samples were placed in the freezer after 60 days of maturation.

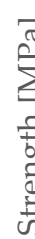

120.0
100.0

80.0

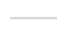

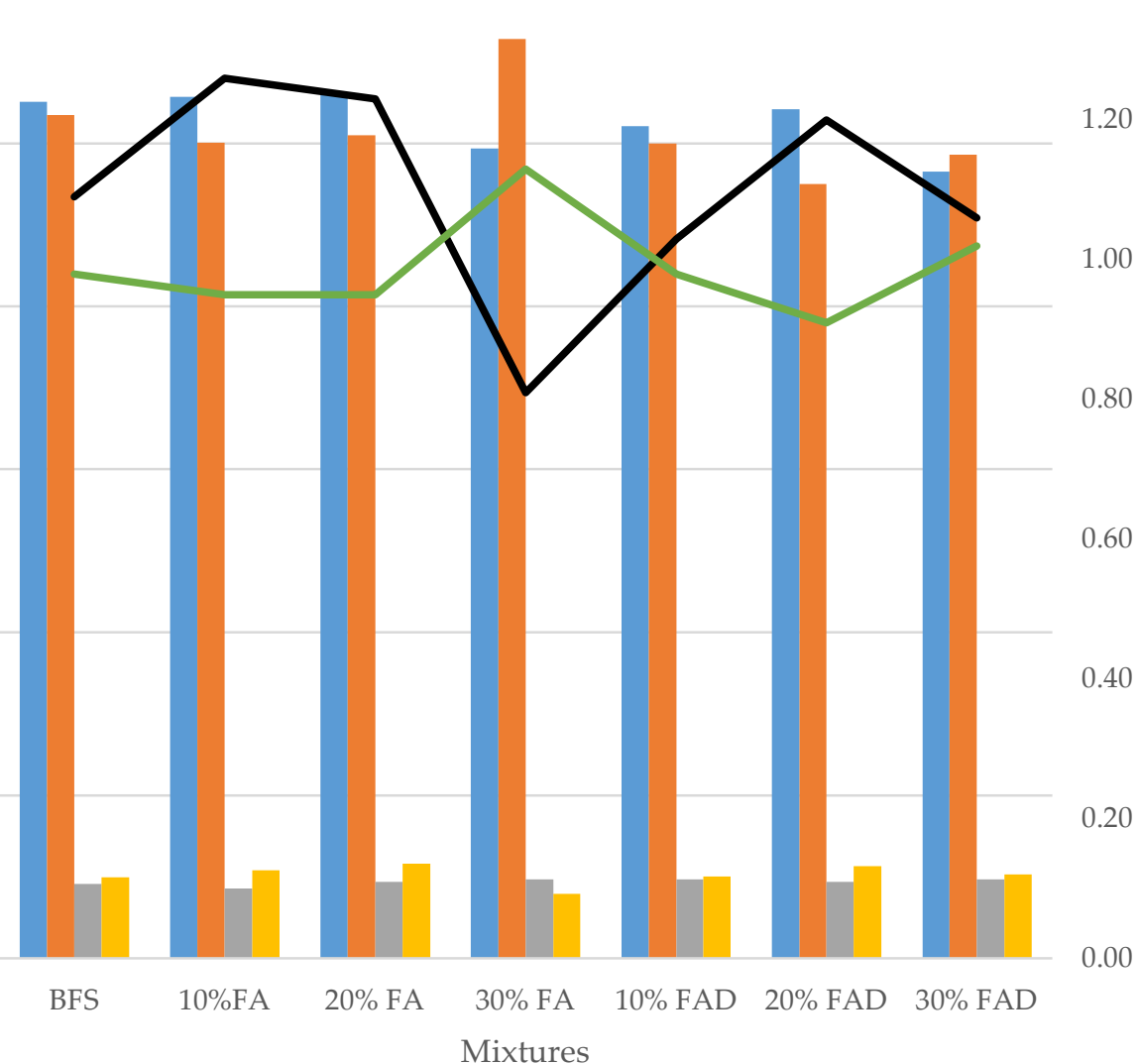

1.40

Compressive strength Ref [MPa]

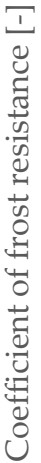

Compressive strength freeze-thaw [MPa]

Flexural strength $\operatorname{Ref}[\mathrm{MPa}]$

$$
60.0
$$

Mixtures

Figure 6. Results of resistance to freeze-thaw.

In terms of resistance to freeze-thaw, prepared mixtures show good resistance and meet the condition that the drop in strength must not fall below $75 \%$ of the strength of the reference series. For flexural strengths, a $26 \%$ increase in strength was even observed for the $10 \%$ FA mixture over the same reference series. The only exception, when there was a significant decrease in strength of almost $20 \%$ was recorded at the mixture of $30 \%$ FA. Paradoxically, as in the only one, a more significant increase in compressive strength was recorded in this mixture, by $13 \%$. With the exception of the $30 \%$ FAD mixture, decreases of compressive strength were observed for frozen samples of all other mixtures.

The authors in [26] also monitored the resistance to freeze-thaw of alkali-activated blast furnace granulated slag. For the mixture activated with activator with a ratio (R/S) of 50/50, similar results were obtained as in this experiment, flexural strengths increased by $5 \%$ after 125 freezing cycles, and compressive strengths were found to decrease by $3 \%$. This research also suggests that potassium hydroxide is not ideal for alkali activation 
of slag as the samples disintegrated after 45 freezing cycles. There was also a significant decrease in flexural strength at mixtures prepared with the activator with a ratio $(\mathrm{R} / \mathrm{S})$ of $70 / 30$, when the decrease was $30 \%$, for compressive strength the decrease was only $10 \%$ [26].

Previous research [18] using identical raw materials that were activated with sodium water glass with silicate modulus of 2 showed slight decreases in compressive strength of only $4 \%$. On the other hand, in the case of flexural strength, increases of strength after 100 cycles of freezing of up to $53 \%$ were recorded [18].

The authors in [30] studied the effect of nanoparticles on freeze-thaw resistance of alkali-activated slag. Three types of nano admixtures were used in the experiment, namely nanosilica, nanoaluminum and nanoclay. These additives were metered into the mixtures in 1, 2 and $3 \%$ by weight. The samples were tested after 90 days of maturation and the compressive strength was monitored after 100, 200 and 300 cycles. The nanoparticles have been found to have a positive effect on compressive strength and resistance to freezethaw. When $3 \%$ by weight of nanosilica was applied, a decrease in compressive strength of $300 \%$ was achieved after 300 cycles, while in the reference series, the decrease was only $6.14 \%$. After the application of nanoaluminum and nanoclay, the lowest decreases were achieved in $2 \%$ by weight of nano admixtures after 200 freeze-thaw cycles. For nanoaluminum, this decrease was $3.98 \%$, while for the reference series the decrease was $5.1 \%$ and for nanoclay the decrease for the reference series was $5.1 \%$ and for $2 \mathrm{wt} \%$ nanoclay $3.59 \%$ [30].

In [23], alkali-activated slag mortars were tested with and without the addition of a cocamide diethanolamine-based aerating additive. 3 mixtures were prepared, in which the alkali content differed. Mortars made of Portland cement CEM I 42.5R and blast furnace cement CEM III/B 42.5R were prepared for comparison. The air content of all alkaliactivated mortars was in the range of $4-5 \%$ before the addition of the aerating agent. After the addition of the additive, the air content was in the range of $10-11 \%$. For both types of cements, the air content after the addition of the additive was $11 \%$. From the compressive strength results of Portland cement, it can be concluded that this mixture was almost unaffected by freeze-thaw processes. While the mixtures prepared from blast furnace cement and two mixtures with higher alkali contents showed decreases in compressive strengths, which ranged from $25-30 \%$. In the mixture which contained the lowest alkali content, the strength drop was $67 \%$. After the addition of the aerating agent, the strength drop was $45 \%$. After adding the aerating additive to the mixture with the highest alkali content, the strength drop was $18 \%$. For blast furnace cement, the decrease in strength after the addition of the aerating additive was $14 \%$. The strength decreases reported are after 150 freezethaw cycles [23].

The authors in [31] studied the freeze-thaw resistance of alkali-activated pastes based on blast furnace granulated slag with a partial replacement by a rice husk ash. The replacement of slag with ash from rice husks was from 0 to $50 \mathrm{wt}$ \%. The loss of compressive strength of the mixture without slag replacement was around $37 \%$, while the mixture with a proportion of $10 \mathrm{wt}$. \% ash from rice husks was a decrease in strength of $22 \%$. From the point of view of the resistance of materials to the effects of freeze-thaw, $10 \%$ by weight appears to be the most optimal replacement for slag with rice husk ash. \%. Up to $30 \mathrm{wt}$. \% the addition of fly ash from rice husks has a positive effect on the resistance to freezethaw. Higher replacement already has a negative impact on the freeze-thaw resistance of the mixtures [31].

As the results in [23 and 26] suggest, the resistance of alkali-activated slag-based materials will depend mainly on the activator and its associated properties, such as type, silicate modulus and total alkalis content. Aeration has also been shown to have a positive effect on the resistance of alkali-activated materials to the effects of freeze-thaw [23].

\subsection{Influence of Leaching in Demineralized Water}


The values of compressive strength, flexural strength and demineralized water influence coefficients for 28 days are given in Figure 7. Samples were placed in demineralized water after 60 days of maturation. $\mathrm{pH}$ of the original demineralized water was 6.5. The values of compressive strength, flexural strength and demineralized water influence coefficients for 1 month are given in Figure 7.
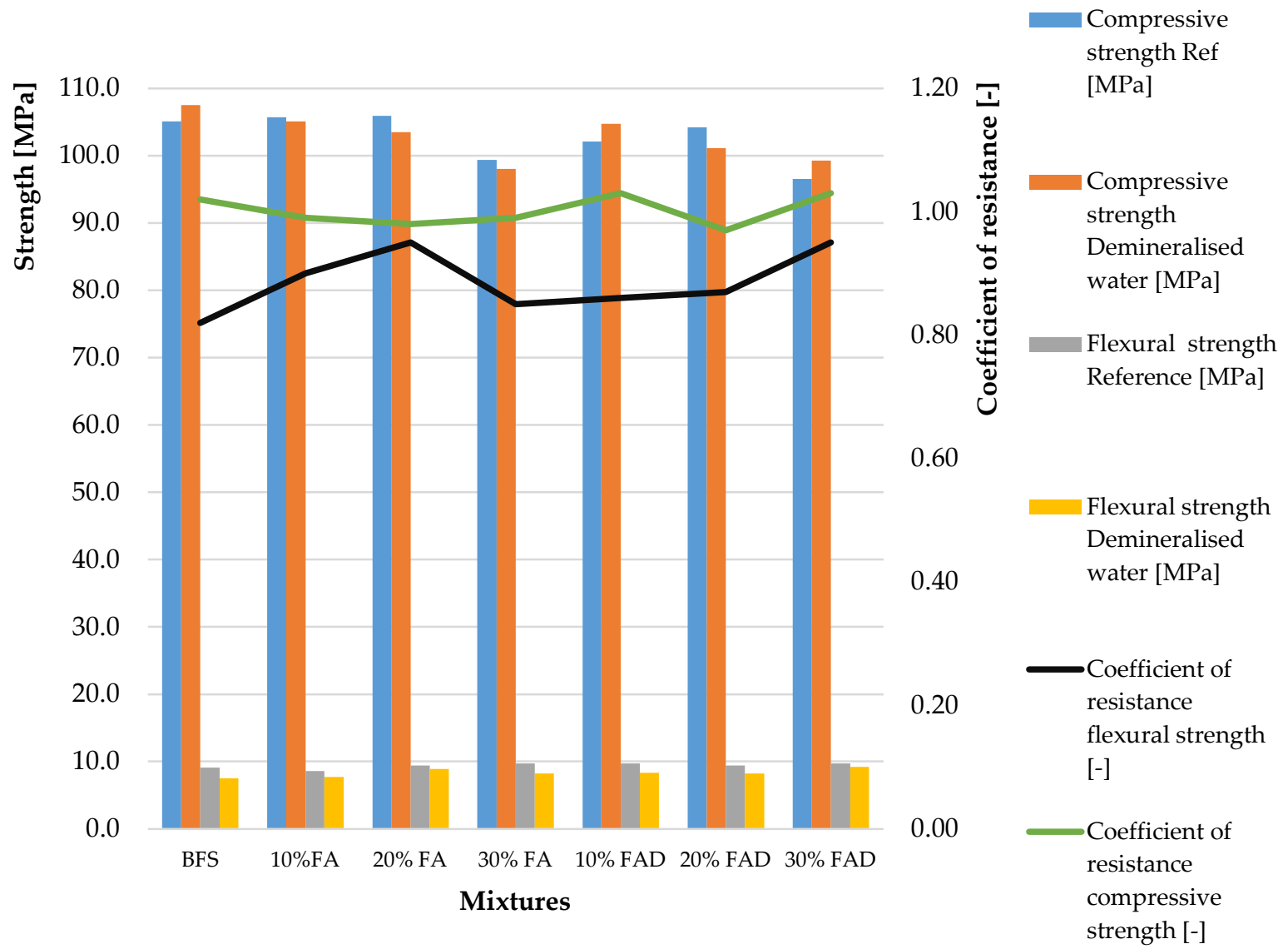

Figure 7. Resistance to aggressive environments.

Leaching in demineralized water had almost no effect on compressive strength. The differences for all mixtures were only within standard deviations. On the other hand, the effect of the pure water on flexural strength was significant. The highest decrease was recorded at BFS, which can be explained by the fact that this mixture has the highest amount of calcium, which is the most susceptible to leaching. But if we take the same condition as for freeze-thaw resistance, that the drop in strength must not fall below 75\% of the reference series, this condition is met by all mixtures.

Previous research [18] has not confirmed the hypothesis that BFS is the most susceptible to a decrease in strength due to leaching, as higher decreases were observed for $10 \%$ FA, 20\% FA and 20\% FAD mixtures, which were about 20\%. The compressive strength coefficients ranged from 1.00 to 1.06 , which are similar to the results in the current research [18].

The authors in [32] studied the leachability and strength decreases of alkali-activated mortars based on blast furnace granulated slag with cesium admixture in the amount of 2 and $5 \%$. Cesium had a positive effect on the strength properties of the prepared mortars, when both mortars with cesium reached higher strengths by 15-25 MPa. The authors preliminarily attribute this increase to the effect of cesium on the dissolution of blast 
furnace granulated slag grains or the structural change of gels in activated slag hydration products. These findings will be further studied. Leach resistance was monitored for 5 days in deionized water. The best leaching resistance was obtained with a $5 \%$ cesium mixture, where the strength drop was $5 \%$ to the reference strength. The largest decrease in strength was recorded for the mixture with $2 \%$ cesium and the decrease was $22 \%$, although this strength was higher than in the original reference series [32].

The authors in [33] studied the properties of alkali-activated materials with different ratios of slag and fly ash. Compressive strengths in three different environments were monitored depending on the age of the samples. Individual samples at different ages (7, 28 and 60) were placed in demineralized water, immersed $1 \mathrm{~mm}$ in demineralized water and left in air at $22 \pm 2{ }^{\circ} \mathrm{C}$ and subsequently tested after 7, 28 and 60 days. Regardless of the ratio between slag and fly ash, age or exposure time, the lowest strengths were always achieved for samples immersed in $1 \mathrm{~mm}$ in demineralized water. In the mixture where there was $100 \%$ by weight of slag, there were only minimal differences between the individual deposits after 28 days of maturation and subsequent exposures. In terms of results, the strength increases at the age time of 60 days when immersed in demineralized water are interesting, while the strengths decreased when stored in demineralized water for 28 days. This applies to mixtures with 100,75 and $50 \%$ by weight of slag. In the mixture with $25 \%$ by weight of slag, all strengths of samples stored in demineralized water increased, regardless of the maturation time or the duration of exposure [33].

In terms of resistance to hungry water simulated by the action of demineralized water, it would be interesting to monitor resistance in the longer term, because in [33] there were increases in strength at a storage time of 60 days compared to a storage period of 28 days. However, the question is whether these increases would continue even after prolonged exposure to demineralized water, or would there be a significant decrease in strength, which would be caused by decalcification of the hydration product C-(A)-S-H gel.

\subsection{Heat Evolution Rates Measurement in Calorimeter}

Monitoring the development of hydration heat during hydration processes on pastes is shown in Figures 8, 9 and 10.

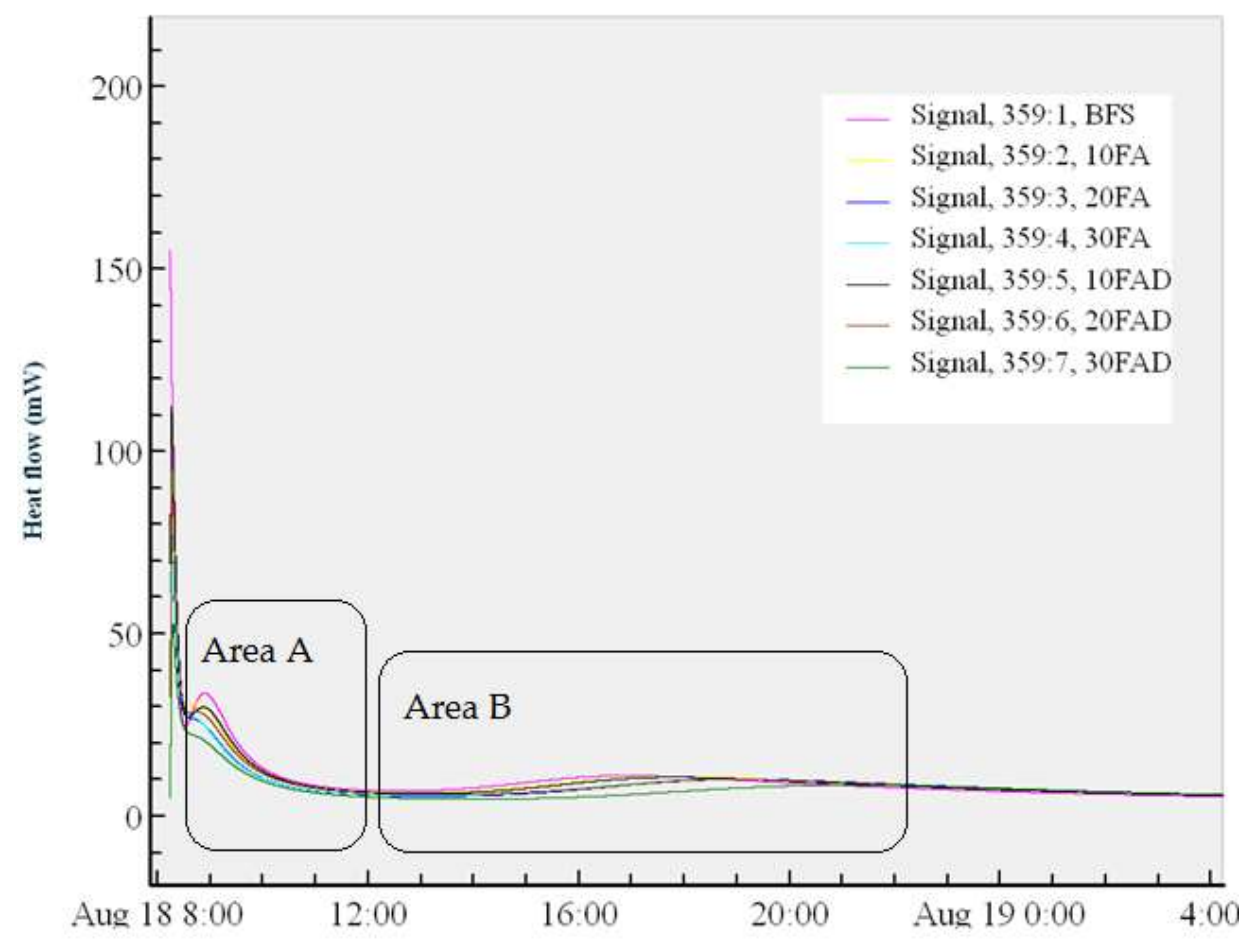


Figure 8. General view on reactions in the calorimeter.

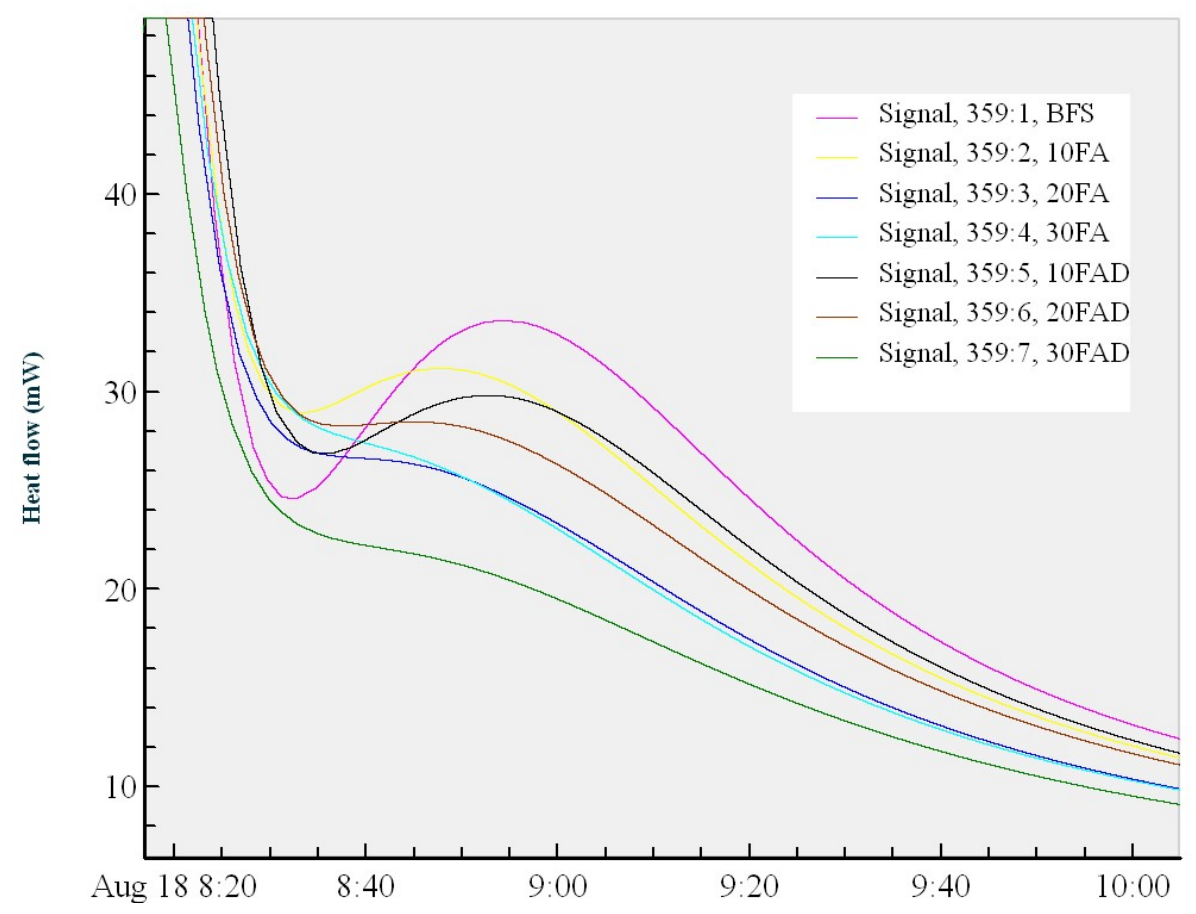

Figure 9. Detailed view of peak 2 in area A.

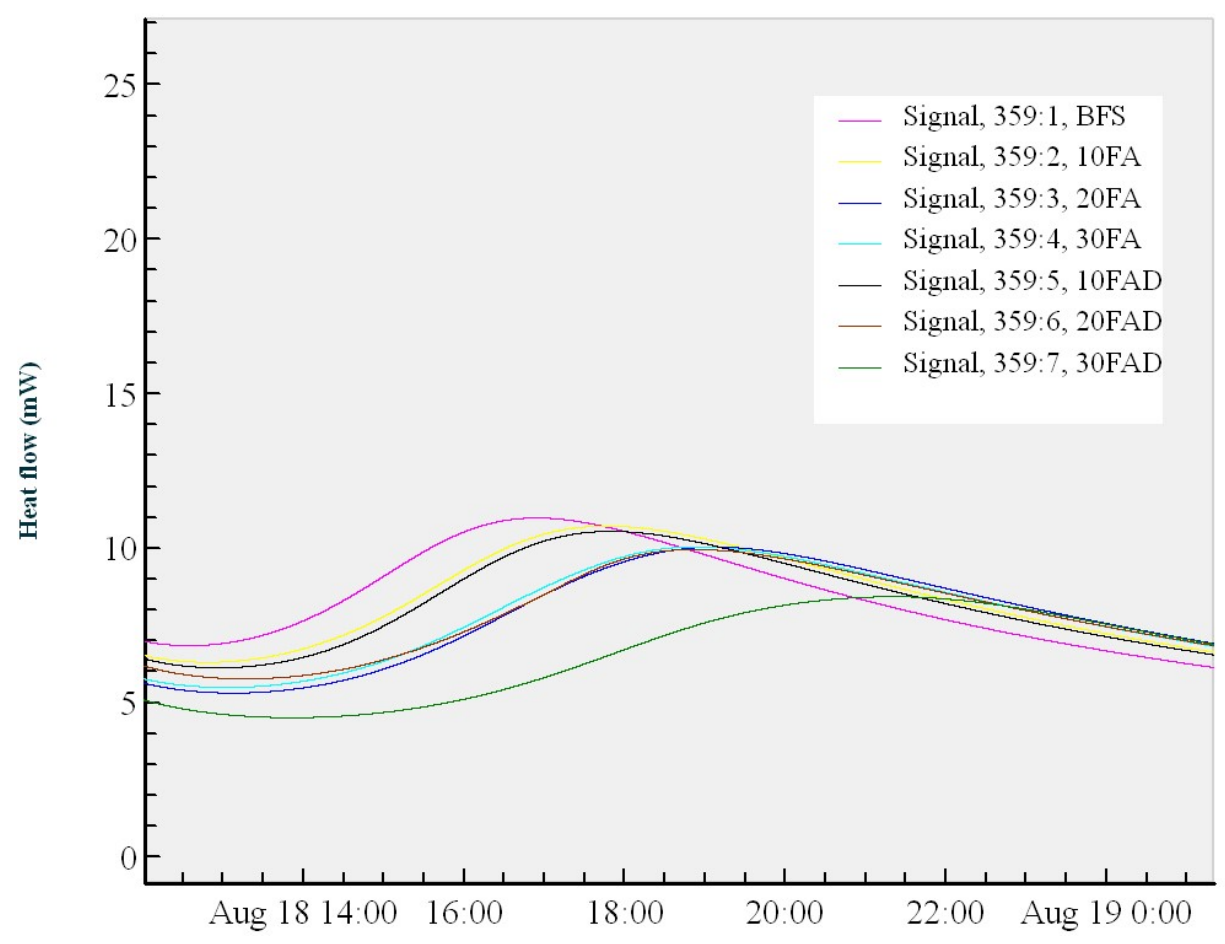

Figure 10. Detailed view of peak 3 in area B.

The highest heat flux caused by the ongoing hydration reactions was recorded for the BFS mixture. This is understandable, as slag reacts much faster than fly ash and is mainly involved in short-term strengths. On the other hand, fly ash is less reactive and in hybrid systems it mainly contributes to long-term strengths. For the fly ash used, these 
assumptions further increase, since these fly ash contains a small amorphous fraction which participates in the reactions. As the replacement of slag with fly ash increases, the heat flux gradually decreases. No increase in heat flux was observed for the $30 \% \mathrm{FA}, \mathrm{FAD}$ mixtures, only a decreasing heat flux curve was flattened, which is clearly seen in Figure 9. The lowest heat flux was recorded for the $30 \%$ FAD mixture. In Figure 10 we see ongoing reactions at a later time of maturation. It can be seen from the resulting curves that the reaction proceeded most rapidly at the BFS mixture, followed by the $10 \%$ FA, FAD mixtures. Only a mixture of $30 \%$ FAD achieved a lower heat flux, the onset of the increase in heat flux took place later than in other mixtures.

The authors in [34] describe the course of reactions in the calorimeter as follows. The first peak is associated with the wettability of slag grains. The second peak region is associated with the formation of a primary C-S-H gel by the reaction of $\mathrm{SiO}_{4}{ }^{4-}$ from water glass and $\mathrm{Ca}^{2+}$ dissolved from the surface of the slag. And the third peak is attributed to the formation of a secondary C-S-H gel. In this experiment, the authors investigated the use of sodium phosphate as a retarder of alkali-activated slag. It was found that the addition of sodium phosphate slows down the hydration of the slag and at dosing of 0.5 and $1.0 \mathrm{wt} \%$ of $\mathrm{P}_{2} \mathrm{O}_{5}$ higher values of compressive strength were achieved after 28 days than in the reference series [34].

It would be interesting to observe the reactions in the calorimeter in the long run, when the authors in [29] attribute decreases of strength to ongoing hydration reactions, which take water from already formed products. However, the question is whether these reactions taking place in a later time period would be shown on the course of the curves in the calorimeter.

\subsubsection{FTIR Analysis}

Figure 11 show the resulting curves of FTIR analysis of individual mixtures of alkaliactivated pastes.

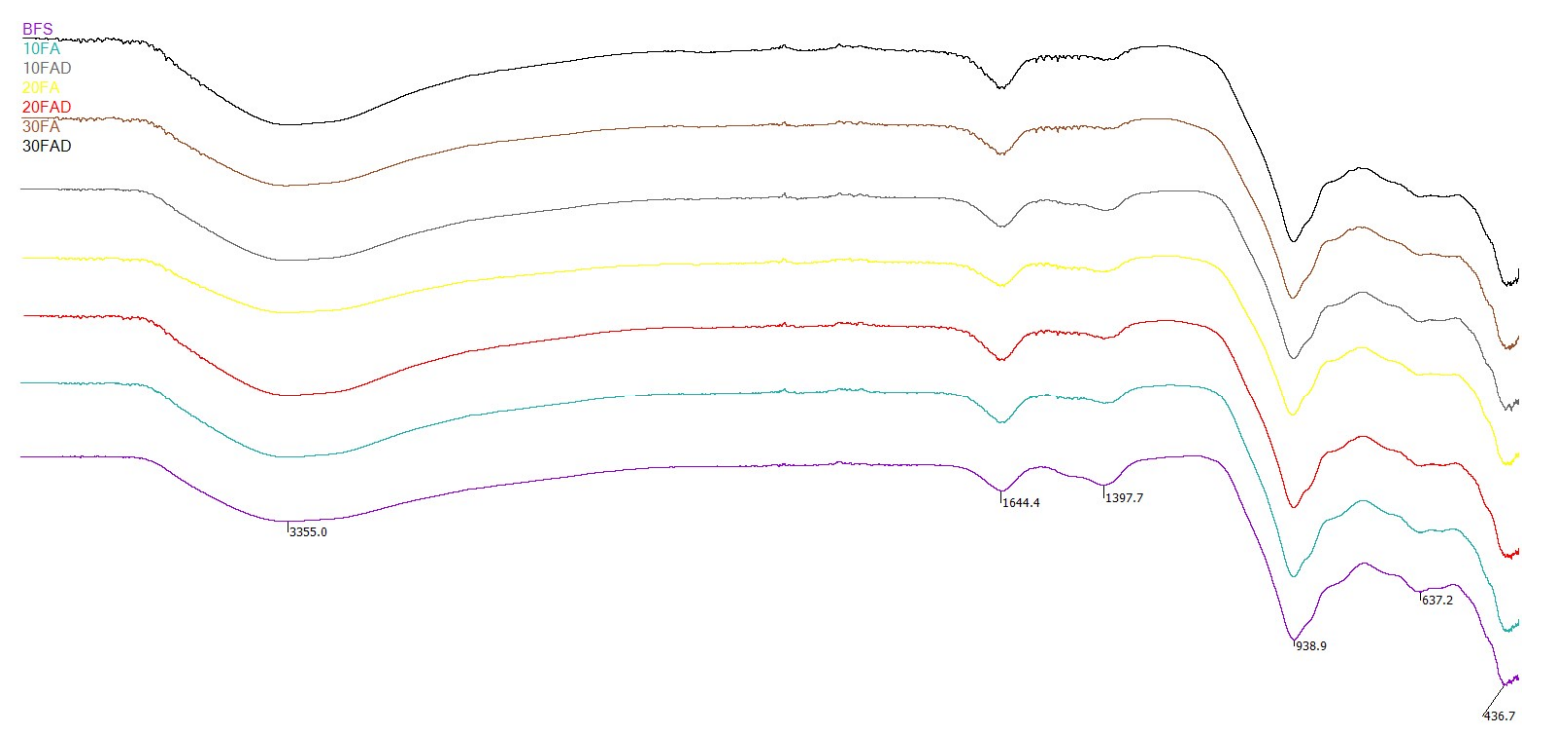

Figure 11. Resulting curves of FTIR analysis.

In the area of 3355 and $1644 \mathrm{~cm}^{-1}$, the water stress $(\mathrm{O}-\mathrm{H})$ and deformation $(\mathrm{H}-\mathrm{OH})$ bands are identified. These areas are caused by the presence of chemically bounded water in the hydrated alkali-activated materials in different spectra. Absorption bands around $1397 \mathrm{~cm}^{-1}$ correspond to $\mathrm{O}-\mathrm{C}-\mathrm{O}$ vibrations in carbonates. The main absorption band of the reaction product is located at around $939 \mathrm{~cm}^{-1}$ in all mixtures, which are assigned to 
the asymmetric stretching vibration of $\mathrm{Si}-\mathrm{O}-\mathrm{T}$ ( $\mathrm{T}=$ tetrahedral $\mathrm{Si}$ or $\mathrm{Al}$ ) terminal (nonbridging) bonds, indicating that the main reaction product is a chain structured C-(A)-S$\mathrm{H}$ type gel. The area moving around $420 \mathrm{~cm}^{-1}$ represents bonds ( $\mathrm{Si}-\mathrm{O}-\mathrm{Si}$ and $\mathrm{O}-\mathrm{Si}-\mathrm{O}$ ) [15, 35-39]. Symmetrical expansion bonds Si-O-Si and Al-O-Si occur in the region of $637 \mathrm{~cm}^{-1}$ [36].

The only major difference in the observed curves is in the area of carbonate bonds around $1397 \mathrm{~cm}^{-1}$, where with increasing fly ash content decreases the intensity of carbonate peak, which corresponds to the statement in [26], where the authors do not anticipate changes in hydration products in hybrid systems, where is slag replaced by fly ash up to $25 \%$ [36].

\section{Conclusions}

This research was focused on the assessment of the effect of denitrification by SNCR method on fly ash for use in hybrid alkali-activated materials based on blast furnace granulated slag. Potassium water glass with silicate modulus of 1 was used as an activator in the experiment.

The results obtained so far show that the use of fly ash after denitrification in hybrid alkali-mixtures does not significantly reduce the observed properties in comparison with the use of conventional fly ash without denitrification.

The results of the experiment showed that there is no significant difference between the properties of mixtures prepared from fly ash after denitrification and without denitrification.

For the strength parameters, the trend of decreasing flexural and compressive strengths, which can be caused by the leaching of alkalis from samples stored for a long time in water, is rather interesting. This phenomenon is currently being investigated and the results of the research will be published soon.

In terms of slag replacement by ash, it can be stated that in most cases the best results are achieved with 10\% slag replacement (by FA and FAD ash), in the case of higher percentages, the strengths usually decrease.

From the point of view of resistance to freeze-thaw, the results of a mixture with $30 \%$ FA seem interesting and debatable. The flexural strengths were the worst in the entire series during freezing cycles, while the compressive strengths of the tested mixture reached the highest values even when comparing with the reference mixture.

The results of resistance to freeze-thaw do not copy the trends of the development of strengths, when the strength parameters gradually decrease with increasing replacement of slag with fly ash. Here, fly ash appears to have a positive effect on the freeze-thaw resistance of tested mixtures.

When testing of leaching in demineralized water, it appears that the partial replacement of slag with fly ash improves the resistance to a decrease in strength. However, as it turns out that alkali leaching can be problematic only after a longer storage period ( 3 or more months), it will be necessary to repeat the test and let the demineralized water act longer so that its effect can be fully manifested.

Monitoring of hydration processes showed the expected results, ie that low-reactivity fly ash with a low proportion of amorphous particles reduces heat flux and contributes to the development of long-term strengths.

FTIR analysis confirmed that the intensity of the carbonate peak decreases in the area of carbonate bonds with increasing ash content.

Author Contributions: L.P.-Conceptualization, methodology, formal analysis, investigation, resources, writing-original draft preparation. J.B.-Methodology, investigation, resources, writing-original draft preparation, supervision. B.V.-Conceptualization, methodology, formal analysis, writing - review and editing. All authors have read and agreed to the published version of the manuscript.

Funding: This research was funded by University specific research project - grant number SP2021/97 -Effect of fly ash on alkali activated concrete based on blast furnace granulated slag 
Acknowledgments: The authors would like to thank the Department of Thermal Engineering from VSB-Technical University of Ostrava for performing XRD and XRF analyzes.

Conflicts of Interest: The authors declare that they have no known competing financial interests or personal relationships that could have appeared to influence the work reported in this paper.

\section{References}

1. Abdollahnejad, Z., Mastali, M., Woof, B., \& Illikainen, M. High strength fiber reinforced one-part alkali activated slag/fly ash binders with ceramic aggregates: Microscopic analysis, mechanical properties, drying shrinkage, and freeze-thaw resistance. Construction and Building Materials 2020, 241, 118129. doi:10.1016/j.conbuildmat.2020.118129.

2. Mastali, M., Kinnunen, P., Dalvand, A., Mohammadi Firouz, R., \& Illikainen, M. Drying shrinkage in alkali-activated binders A critical review. Construction and Building Materials 2018, 190, 533-550. doi:10.1016/j.conbuildmat.2018.09.125.

3. Humad, A. M., Kothari, A., Provis, J. L., \& Cwirzen, A. The Effect of Blast Furnace Slag/Fly Ash Ratio on Setting, Strength, and Shrinkage of Alkali-Activated Pastes and Concretes. Frontiers in Materials 2019, 6. doi:10.3389/fmats.2019.00009.

4. Bernal, S. A., Provis, J. L., Walkley, B., San Nicolas, R., Gehman, J. D., Brice, D. G., ... van Deventer, J. S. J. Gel nanostructure in alkali-activated binders based on slag and fly ash, and effects of accelerated carbonation. Cement and Concrete Research 2013, 53, 127-144. doi:10.1016/j.cemconres.2013.06.007.

5. Keulen, A., van Zomeren, A., \& Dijkstra, J. J. Leaching of monolithic and granular alkali activated slag-fly ash materials, as a function of the mixture design. Waste Management 2018, 78, 497-508. doi:10.1016/j.wasman.2018.06.019.

6. Wang, W.-C., Wang, H.-Y., \& Lo, M.-H. The fresh and engineering properties of alkali activated slag as a function of fly ash replacement and alkali concentration. Construction and Building Materials 2015, 84, $224-229$. doi:10.1016/j.conbuildmat.2014.09.059.

7. Hu, X., Shi, C., Shi, Z., \& Zhang, L. Compressive strength, pore structure and chloride transport properties of alkali-activated slag/fly ash mortars. Cement and Concrete Composites 2019, 104, 103392. doi:10.1016/j.cemconcomp.2019.103392

8. Gao, X., Yu, Q. L., \& Brouwers, H. J. H. Properties of alkali activated slag-fly ash blends with limestone addition. Cement and Concrete Composites 2015, 59, 119-128. doi:10.1016/j.cemconcomp.2015.01.007.

9. h, J. E., Monteiro, P. J. M., Jun, S. S., Choi, S., \& Clark, S. M. The evolution of strength and crystalline phases for alkali-activated ground blast furnace slag and fly ash-based geopolymers. Cement and Concrete Research 2010, 40(2), 189-196. doi:10.1016/j.cemconres.2009.10.010.

10. Marjanović, N., Komljenović, M., Baščarević, Z., Nikolić, V., \& Petrović, R. Physical-mechanical and microstructural properties of alkali-activated fly ash-blast furnace slag blends. Ceramics International 2015, 41(1), 1421-1435. doi:10.1016/j.ceramint.2014.09.075.

11. Alcamand, H. A., Borges, P. H. R., Silva, F. A., \& Trindade, A. C. C. The effect of matrix composition and calcium content on the sulfate durability of metakaolin and metakaolin/slag alkali-activated mortars. Ceramics International 2018, 44(5), 5037-5044. doi:10.1016/j.ceramint.2017.12.102.

12. Wong, J. K. H., Kok, S. T., \& Wong, S. Y. Fibers, Geopolymers, Nano and Alkali-Activated Materials forDeep Soil Mix Binders. Civil Engineering Journal 2020, 6(4), 830-847. doi:10.28991/cej-2020-03091511.

13. Ye, H. Nanoscale attraction between calcium-aluminosilicate-hydrate and Mg-Al layered double hydroxides in alkali-activated slag. Materials Characterization 2018, 140, 95-102. doi:10.1016/j.matchar.2018.03.049.

14. Ye, H., Fu, C., \& Yang, G. Influence of dolomite on the properties and microstructure of alkali-activated slag with and without pulverized fly ash. Cement and Concrete Composites 2019, 103, 224-232. doi:10.1016/j.cemconcomp.2019.05.011.

15. Živica, V. Effects of type and dosage of alkaline activator and temperature on the properties of alkali-activated slag mixtures. Construction and Building Materials 2007, 21(7), 1463-1469. doi:10.1016/j.conbuildmat.2006.07.002

16. Palacios, M., Alonso, M. M., Varga, C., \& Puertas, F. Influence of the alkaline solution and temperature on the rheology and reactivity of alkali-activated fly ash pastes. Cement and Concrete Composites 2019, 95, $277-284$. doi:10.1016/j.cemconcomp.2018.08.010

17. Ismail, I.; A. Bernal, S.; Provis, J.L.; Hamdan, S.; Van Deventer, J.S.J. Microstructural changes in alkali activated fly ash/slag geopolymers with sulfate exposure. Mater. Struct. 2012, 46, 361-373, doi:10.1617/s11527-012-9906-2.

18. Procházka, L.; Boháčová, J. Effect of Admixtures on Durability Characteristics of Fly Ash Alkali-activated Material. Emerg. Sci. J. 2020, 4, 493-502, doi:10.28991/esj-2020-01247.

19. Kotouč Štramberk. 2018. Available online: https://www.cemix.cz/kotouc/cz (accessed on 12 January 2018).

20. ČSN EN 196-1 Methods of Testing Cement-Part 1: Determination of Strength; Office for Technical Standardization, Metrology and State Testing: Prague, Czech Republic, 2005; pp. 5-40.

21. Procházka, L., \& Boháčová, J. Verification of Durability Properties of Alkali-Activated Materials Based on Blast Furnace Slag with Fly Ash. Solid State Phenomena 2020, 309, 93-97. doi:10.4028/www.scientific.net/ssp.309.93

22. Procházka, L., \& Mec, P. Possibility of using fly ash after denitrification by SNCR as admixture in alkali-activated materials. Materials Today: Proceedings 2021, 37, 42-47. doi:10.1016/j.matpr.2020.04.594

23. Coppola, L.; Coffetti, D.; Crotti, E.; Gazzaniga, G.; Pastore, T. The Durability of One-Part Alkali-Activated Slag-Based Mortars in Different Environments. Sustainability 2020, 12, 3561. https://doi.org/10.3390/su12093561

24. ČSN EN 196-3 Methods of Testing Cement-Part 3: Determination of Setting Times and Soundness; Office for Technical Standardization, Metrology and State Testing: Prague, Czech Republic, 2006; pp. 5-40. 
25. ČSN 722452 Frost Resistance Test of Mortar; Office for Technical Standardization, Metrology and State Testing: Prague, Czech Republic, 1970; Classifier 722452.

26. Bilek, V.; Sucharda, O.; Bujdos, D. Frost Resistance of Alkali-Activated Concrete-An Important Pillar of Their Sustainability. Sustainability 2021, 13, 473. https://doi.org/10.3390/su13020473.

27. Wang, W.-C., Wang, H.-Y., \& Lo, M.-H. The fresh and engineering properties of alkali activated slag as a function of fly ash replacement and alkali concentration. Construction and Building Materials 2015, 84, $224-229$. doi:10.1016/j.conbuildmat.2014.09.059

28. Hu, X., Shi, C., Shi, Z., \& Zhang, L. Compressive strength, pore structure and chloride transport properties of alkali-activated slag/fly ash mortars. Cement and Concrete Composites 2019, 104, 103392. doi:10.1016/j.cemconcomp.2019.103392

29. Fang, S., Lam, E. S. S., Li, B., \& Wu, B. Effect of alkali contents, moduli and curing time on engineering properties of alkali activated slag. Construction and Building Materials 2020, 249, 118799. doi:10.1016/j.conbuildmat.2020.118799

30. Shahrajabian, F., \& Behfarnia, K. The effects of nano particles on freeze and thaw resistance of alkali-activated slag concrete. Construction and Building Materials 2018, 176, 172-178. doi:10.1016/j.conbuildmat.2018.05.033

31. Zhu, H., Zhai, M., Liang, G., Li, H., Wu, Q., Zhang, C., \& Hua, S. Experimental study on the freezing resistance and microstructure of alkali-activated slag in the presence of rice husk ash. Journal of Building Engineering 2021, $38,102173$. doi:10.1016/j.jobe.2021.102173

32. Komljenović, M. et al., Immobilization of cesium with alkali-activated blast furnace slag. Journal of Hazardous Materials 2020, 388, p.121765. Available at: http://dx.doi.org/10.1016/j.jhazmat.2019.121765.

33. Yao, X., Yang, T., \& Zhang, Z. Compressive strength development and shrinkage of alkali-activated fly ash-slag blends associated with efflorescence. Materials and Structures 2015, 49(7), 2907-2918. doi:10.1617/s11527-015-0694-3

34. Kalina, L.; Bílek, V.; Novotný, R.; Mončeková, M.; Másilko, J.; Koplík, J. Effect of Na3PO4 on the Hydration Process of AlkaliActivated Blast Furnace Slag. Materials 2016, 9, 395. https://doi.org/10.3390/ma9050395.

35. Gao, X.; Yu, Q.; Brouwers, H. Properties of alkali activated slag-fly ash blends with limestone addition. Cem. Concr. Compos. 2015, 59, 119-128, doi:10.1016/j.cemconcomp.2015.01.007.

36. Ismail, I.; A. Bernal, S.; Provis, J.; Nicolas, R.S.; Hamdan, S.; van Deventer, J.S. Modification of phase evolution in alkali-activated blast furnace slag by the incorporation of fly ash. Cem. Concr. Compos. 2014, 45, 125-135, doi:10.1016/j.cemconcomp.2013.09.006.

37. Puertas, F.; Jimenez, A.M.F. Mineralogical and microstructural characterisation of alkali-activated fly ash/slag pastes. Cem. Concr. Compos. 2003, 25, 287-292, doi:10.1016/s0958-9465(02)00059-8.

38. De Gutierrez, R.M.; Robayo, R.A.; Gordillo, M. Natural pozzolan-and granulated blast furnace slag-based binary geopolymers. 2016, 66, e077, doi:10.3989/mc.2016.03615.

39. Silva, I.; Castro-Gomes, J.P.; Albuquerque, A. Effect of immersion in water partially alkali-activated materials obtained of tungsten mine waste mud. Constr. Build. Mater. 2012, 35, 117-124, doi:10.1016/j.conbuildmat.2012.02.069. 